\title{
Study on the Integration of Mathematical Modeling into Function of Complex Variable
}

\author{
Haijian Cui \\ Nanchang Institute of Science \& Technology
}

\begin{abstract}
Keywords: Function of Complex Variables; Mathematical Modeling; Mathematics Application Ability; Concurrent Education
\end{abstract}

\begin{abstract}
Function of complex variable is not only an important specialized course in university mathematics and applied mathematics but also a basic major course in terms of electric, automatic and communication departments. Besides, the results of various subject areas are formed with function of complex variable as the basis. Especially in recent years, with the rapid development of communication technology, the theory as well as approaches of function of complex variable are expanded and perfected and various talents are able to apply its theory as well as approaches into engineering practice, which ask new requirement for the teaching course. This paper studies on the integration of mathematical modelinginto function of complex variable into so as to further strengthen the practical function based on updating teaching contents, introducing modeling cases, reforming teaching approaches etc.
\end{abstract}

\section{Introduction}

Functions of complex variables is an important basic theory course for students studying mathematics in universities, which is an important branch of mathematics and a crucial part for university mathematical teaching. This course is offered in the junior year and students have already learned mathematical analysis for one and a half year or two years which help them lay a foundation. However, students cannot totally understand relative knowledge about mathematical analysis because while taking about it in the function of complex variable class, it seems very difficult for them.

The focus of function of complex variable is to differ the nature of it from mathematical analysis and this paper will introduce some important mathematical idea and teaching approaches. In teaching, we have to be diligent in thinking, be good at comparing, focus on both similarities and clear the difference. Only in this way, can we understand the nature and learn to achieve mastery through a comprehensive study of the subject. At present, there are not enough materials talking about the reform of function of complex variables in universities. In order to promote the research, improve the teaching effect, this paper combines modern innovation with function of complex variables as we'll as mathematical modeling in order to cultivate students' practical ability and comes up with the idea of concurrent education to help students absorb knowledge easily.

\section{Concurrent Education}

Concurrent education means that teachers deal with two subjects with similar logic based on same or similar theories so as to help students learn other subjects by referring to one subject which can also improve their theoretical knowledge. Function of complex variables is a follow-up course of mathematical analysis, which takes up an important place in the whole course system. What's more, its theoretical formation, development and ideas have a long history and with lively mathematical bases.

First of all, we cannot think that mathematical analysis and function of complex variable are totally independent and mutually exclusive. During the teaching, we can demonstrate their relation by some practical cases.

Second, teachers have to highlight different theories of a same concept with theoretical reasoning as well as positive and negative examples, which should be clear so as to impress on students. 
Finally, we have to cultivate students' ability to summarize the similarities as well as differences of mathematical analysis and function of complex variables. After each chapter, we have to ask students to design a sheet on their own, showing how differently they can use the same function while facing different fields so as to help them flexibly use these functions.

\section{Integration of Mathematical Modeling into Function of Flexible Variables}

At present, the class teaching of function of complex variables is divorced from its powerful application. Classroom teaching focus on the basic ideas, approaches and theories, ignoring the application background of relative theories. As a result, students cannot apply it into practice and realize its value.

The divorce of classroom teaching and practice is not beneficial for students to apply professional knowledge to solve practical problems and an effective way to integrate them is mathematical modeling. While teaching, teachers should combine the application background and prospects, adopt proper cases so as to help students clearly understand how to use theoretical knowledge to solve real problem and how to closely combine theoretical approaches with real problems based on modeling. Only in this way, can they keep pace with the times and become talents with theoretical knowledge and strong practical ability.

The nature of mathematical modeling is to adopt mathematical theories to describe the objective law of real problems so as to scientifically and properly guide social production and life. Integrating mathematical modeling into function of complex variables cannot only mobilize students' subjective enthusiasm but also help them understand its application approaches and meaning, and meanwhile improve their mathematical modeling ability. So, it is necessary and profound to integrate mathematical modeling into function of complex variable teaching class.

\section{Approaches to Integrate Function of Complex Variable into Mathematical Modeling}

In real teaching process, we have adopted some reform measures in terms of teaching contents, approaches, and examination contents which have achieved good results.

Update Teaching Contents, Integrate Modeling Cases. Concerning the facts that function of complex variables are widely used in various fields, and we can integrate some mature, and cutting edge results or practical cases into teaching. At the same time, we have to take into account students' psychological awareness; ideas etc. and not choose complicated cases. Furthermore, any chosen case should not only reflect the nature of function of complex variable but also be clear, which can ignite students' interest and help them know that we can see it in real life around to avoid the idea that it is useless. It asks as to select proper modeling cases, optimize teaching contents, and highlight the practicability of courses to finally cultivate applied talents.

Reform Teaching Approaches, Infiltrate the Ideas of Modeling. By properly introducing modeling cases in function of complex variable teaching, we cannot only ignite students' interests and combine theory with practice but also gradually infiltrate the ideas of modeling to cultivate students' ability to adopt mathematical modeling to solve real problems which can cultivate talents with strong mathematical modeling ability. Furthermore, the application ability of university students are not cultivated in mathematical modeling class but through reforming the original teaching methods and integrating mathematics into each subjects.

\section{Conclusion}

It takes a long time to integrate mathematical modeling into function of complex variables. This paper describes function of complex variables, innovates the current teaching contents, combines the real condition to analyze the function of concurrent education and the teaching ideas combing mathematical modeling. Based on this, it suggests to choose proper teaching approaches based on reality, which provides references for learners. This paper tells us that we have to explore more betters approaches and integrate mathematical modeling ideas to constantly perfect the teaching 
methods.

\section{References}

[1] Morgan J A, Rhodes D. Mathematical modeling of plant metabolic pathways. [J]. Metabolic Engineering, 2002, 4(1):80-89.

[2] Alexiades V, Solomon A D, Lunardini V J. Mathematical Modeling of Melting and Freezing Processes [J]. Journal of Solar Energy Engineering, 1993, 115(2):121.

[3] Mantzaris N V, Webb S, Othmer H G. Mathematical modeling of tumor-induced angiogenesis. [J]. Journal of Mathematical Biology, 2004, 49(2):111-187.

[4] Drew D A. Mathematical modeling of two-phase flow [J]. Annual Review of Fluid Mechanics, 1983, 15:261-291.

[5] Bier M , Palusinski O A, Mosher R A, et al. Electrophoresis: mathematical modeling and computer simulation.[J]. Science, 1983, 219(4590):1281-7.

[6] He S, Li Y, Wang R Z. Progress of mathematical modeling on ejectors [J]. Renewable \& Sustainable Energy Reviews, 2009, 13(8):1760-1780.

[7] Aliev M K, Saks V A. Compartmentalized energy transfer in cardiomyocytes: use of mathematical modeling for analysis of in vivo regulation of respiration. [J]. Bmj, 1997, 314(7098):1875-1879.

[8] Siepmann J, Siepmann F. Mathematical modeling of drug delivery [J]. International Journal of Pharmaceutics, 2008, 364(2):328-343.

[9] Dutil Y, Rousse D R, Salah N B, et al. A review on phase-change materials: Mathematical modeling and simulations [J]. Renewable \& Sustainable Energy Reviews, 2011, 15(1):112-130.

[10]Singh V P, Woolhiser D A. Mathematical Modeling of Watershed Hydrology [J]. Journal of Hydrologic Engineering, 2014, 7(4):270-292.

[11]Siepmann J, Peppas N A. Mathematical modeling of controlled drug delivery.[J]. Advanced Drug Delivery Reviews, 2001, 48(2-3):137-8.

[12] Smolen P, Baxter D A, Byrne J H. Mathematical modeling of gene networks.[J]. Neuron, 2000, 26(3):567-580. 